\title{
BMJ Open Sexual violence and neonatal outcomes: a Norwegian population-based cohort study
}

\author{
Lena Henriksen, ${ }^{1}$ Berit Schei, ${ }^{2,3}$ Siri Vangen, ${ }^{4}$ Mirjam Lukasse ${ }^{5}$
}

To cite: Henriksen $\mathrm{L}$, Schei B, Vangen $\mathrm{S}$, et al. Sexual violence and neonatal outcomes: a Norwegian population-based cohort study. BMJ Open 2014;4: e005935. doi:10.1136/ bmjopen-2014-005935

- Prepublication history for this paper is available online. To view these files please visit the journal online (http://dx.doi.org/10.1136/ bmjopen-2014-005935).

Received 19 June 2014 Revised 8 September 2014 Accepted 24 September 2014

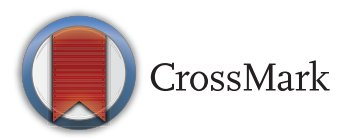

For numbered affiliations see end of article.

Correspondence to Lena Henriksen; uxhelz@ous-hf.no

\section{ABSTRACT}

Objective: The objective of this study was to explore the association between sexual violence and neonatal outcomes.

Design: National cohort study.

Setting: Women were recruited to the Norwegian Mother and Child Cohort Study (MoBa) while attending routine ultrasound examinations from 1999 to 2008.

Population: A total of 76870 pregnant women. Methods: Sexual violence and maternal characteristics were self-reported in postal questionnaires during pregnancy. Neonatal outcomes were retrieved from the Medical Birth Registry of Norway (MBRN). Risk estimations were performed with linear and logistic regression analysis. Outcome measures: gestational age at birth, birth weight, preterm birth (PTB), low birth weight (LBW) and small for gestational age (SGA).

Results: Of 76870 women, $18.4 \%$ reported a history of sexual violence. A total of $4.7 \%$ delivered prematurely, $2.7 \%$ had children with a birth weight $<2500 \mathrm{~g}$ and $8.1 \%$ children were small for their gestational age. Women reporting moderate or severe sexual violence (rape) had a significantly reduced gestational length (2 days) when the birth was provider-initiated in an analysis adjusted for age, parity, education, smoking, body mass index and mental distress. Those exposed to severe sexual violence had a significantly reduced gestational length of 0.51 days with a spontaneous start of birth. Crude estimates showed that severe sexual violence was associated with PTB, LBW and SGA. When controlling for the aforementioned sociodemographic and behavioural factors, the association was no longer significant.

Conclusions: Sexual violence was not associated with adverse neonatal outcomes. Moderate and severe violence had a small but significant effect on gestational age; however, the clinical influence of this finding is most likely limited. Women exposed to sexual violence in this study reported more of the sociodemographic and behavioural factors associated with PTB, LBW and SGA compared with non-abused women.

\section{INTRODUCTION}

Preterm birth (PTB) is a common and costly health problem. ${ }^{1}{ }^{2}$ Approximately 1 in 10

\section{Strengths and limitations of this study}

- This study was based on information from a large population-based study described as sufficient for large-scale epidemiological studies.

- All outcomes were collected prospectively from a quality-assessed birth register.

- The setting, with small social and health inequalities, was suitable to isolate the effect of sexual violence on adverse neonatal outcomes.

- A non-validated instrument for measuring of the exposure variable was a limitation to this study.

babies are born preterm worldwide, and prematurity is considered to be the leading cause of death for newborns. ${ }^{2}$ Low birth weight (LBW) can be a consequence of PTB or intrauterine growth restriction, the latter leading to the birth of small for gestational age (SGA) infants. ${ }^{3}$ Research has suggested some biological risk factors for PTB and LBW: multiple pregnancies, a previous PTB and uterine or placental abnormalities. ${ }^{1}{ }^{3}$ Studies also emphasise other, less understood factors for PTB and LBW. ${ }^{1}$ These are maternal age, socioeconomic status, ethnicity, maternal weight, substance abuse, stress, depression and violence. ${ }^{124}$

Violence against women is a significant public health problem, and a recent report from the WHO states that $35 \%$ of women worldwide have experienced either physical and/or sexual intimate partner violence or non-partner sexual violence. ${ }^{5}$ A pregnancy does not protect women from violence, and the prevalence of physical or sexual violence during pregnancy ranges from $3.4 \%$ to $11 \%$ in high-income countries. ${ }^{6}$ It is recognised that violence has an adverse impact on women's physical, sexual, reproductive and mental health. ${ }^{5} 7$

A connection between PTB or LBW and violence against women has been reported, but the association is supported as well as contradicted. ${ }^{5-20}$ Several pathways between 
sexual violence and adverse pregnancy outcomes are suggested. ${ }^{5}$ A direct pathway of sexual violence can result in immediate complications such as bleeding and rupture of membranes, which can lead to a PTB. ${ }^{5}{ }^{16}$ Other, more indirect pathways are suggested mediated by stress and stress responses ${ }^{18}$ or by behavioural factors such as smoking or substance abuse, used to cope with the negative consequences of violence. ${ }^{5}$

Studies have primarily addressed physical abuse during pregnancy and PTB or $\mathrm{LBW}^{8}$ 10 $^{11}$ 16-19 $^{21}$ or child sexual abuse and PTB/LBW. ${ }^{12}$ Results from a new meta-analysis published in the recent WHO report ${ }^{5}$ have demonstrated an association between intimate partner violence, including physical and sexual abuse, and PTB with an adjusted OR (AOR) of 1.41 (95\% CI 1.21 to 1.62 ) and AOR of 1.16 (95\% CI 1.02 to 1.29 ) with $\mathrm{LBW}^{5}$ However, studies that have investigated the impact of sexual violence on neonatal outcomes specifically are limited and few population-based studies with large sample sizes that enable controlling for confounding variables have been conducted. ${ }^{5}{ }^{11}$ The Norwegian Mother and Child Cohort Study (MoBa) is a population-based prospective cohort study of pregnant women, which includes measurements of lifetime sexual violence, sexual violence during pregnancy and other relevant covariates, which makes it suitable to examine associations between sexual violence and neonatal outcome. In this study, we assessed the relationship between sexual violence and gestational age at birth and birth weight. Additionally, we explored the associations between sexual violence and PTB, LBW and SGA.

\section{METHODS}

This study was a subproject in the MoBa study that was conducted by the Norwegian Institute of Public health from 1999 to 2008. ${ }^{22}$ All pregnant women in Norway were eligible to participate in $\mathrm{MoBa}$, and they were recruited during their routine fetal ultrasound examination. Of the invited women, $40.6 \%$ consented to participate. Data were obtained through extensive self-administered questionnaires that contained demographic factors, general health, reproductive history and questions about maternal health status during pregnancy. Our analyses were based on questionnaire 1 (Q1), which was completed during (approximately) gestational week 17, and Q3, which was completed during (approximately) gestational week 30. Data from MoBa were linked with data from the Medical Birth Registry of Norway (MBRN), which provided information on pregnancy and birth outcome. The current study is based on version VI of the quality-assured data files released for research in 2011. The MoBa study is described in detail elsewhere. ${ }^{22}$ The questionnaires that were used in MoBa are available at the internet-site: http://www.fhi.no/studier/den-norske-mor-ogbarn-undersokelsen/sporreskjemaer

\section{Study population}

This study included women who had a singleton birth between 22 and 44 weeks of gestation, who completed Q1 and Q3, had MBRN data available and participated for the first time (79 363 women). While a pregnancy is the observation unit in the MoBa study, women are the observation unit in our study; hence, the exclusion of 13475 pregnancies of women who participated more than once. We excluded 703 women who did not answer the questions on sexual violence. Further, we excluded records with missing data on gestational length $(n=297)$ and birth weight $(n=41)$. We also excluded six children with birth weight $<500 \mathrm{~g}$ and four children with birth weight $>6000 \mathrm{~g}$, leaving a study sample of 76870 women (figure 1).

\section{Variables \\ Exposure variable}

The exposure variable was collected from Q1. Women were asked if they had been pressured or forced into sexual relations. There were four possible answer options: (1) No, never; (2) Yes, pressured; (3) Yes, forced with violence; or (4) Yes, raped. A positive answer was defined as having experienced sexual violence. Women with more than one positive answer were classified according to the most severe level reported. The answering options were coded into three levels of severity for the sexual violence: (1) mild (pressured); (2) moderate (forced with violence) and (3) severe (raped). Women could also indicate when the violence had taken place: (1) during this pregnancy; (2) during the last 6 months before pregnancy; or (3) earlier. Approximately 1700 women who filled out the first version of Q1 had the answering options earlier and during the last 12 month when assessing time. We therefore created the variables previous and recent sexual violence, with 'recent' containing sexual violence during the last 12 months, including the current pregnancy. Among the women who participated several times we included the first pregnancy only to ensure that the exposure was included only once per woman. More details about the exposure variable can be found in our previous studies $^{2324}$ and in online supplementary table S1.

\section{Outcome variables}

All outcome variables were obtained from the MBRN. Gestational age at birth in days was based on ultrasound at (approximately) gestational week 18. For women with no ultrasound, the gestational age was based on the last menstrual period $(1.7 \%)$. PTB was defined as a gestational age $<37$, LBW as a birth weight $<2500 \mathrm{~g}$, and SGA was defined as birth weight below the 10th centile for the gestational age at birth. SGA was calculated using Norwegian specific fetal growth tables by Skjaerven et al..$^{25}$

\section{Adjusting variables}

Maternal age, parity, socioeconomic status, smoking and body mass index (BMI) were considered as possible 
Figure 1 Inclusion and exclusion process.

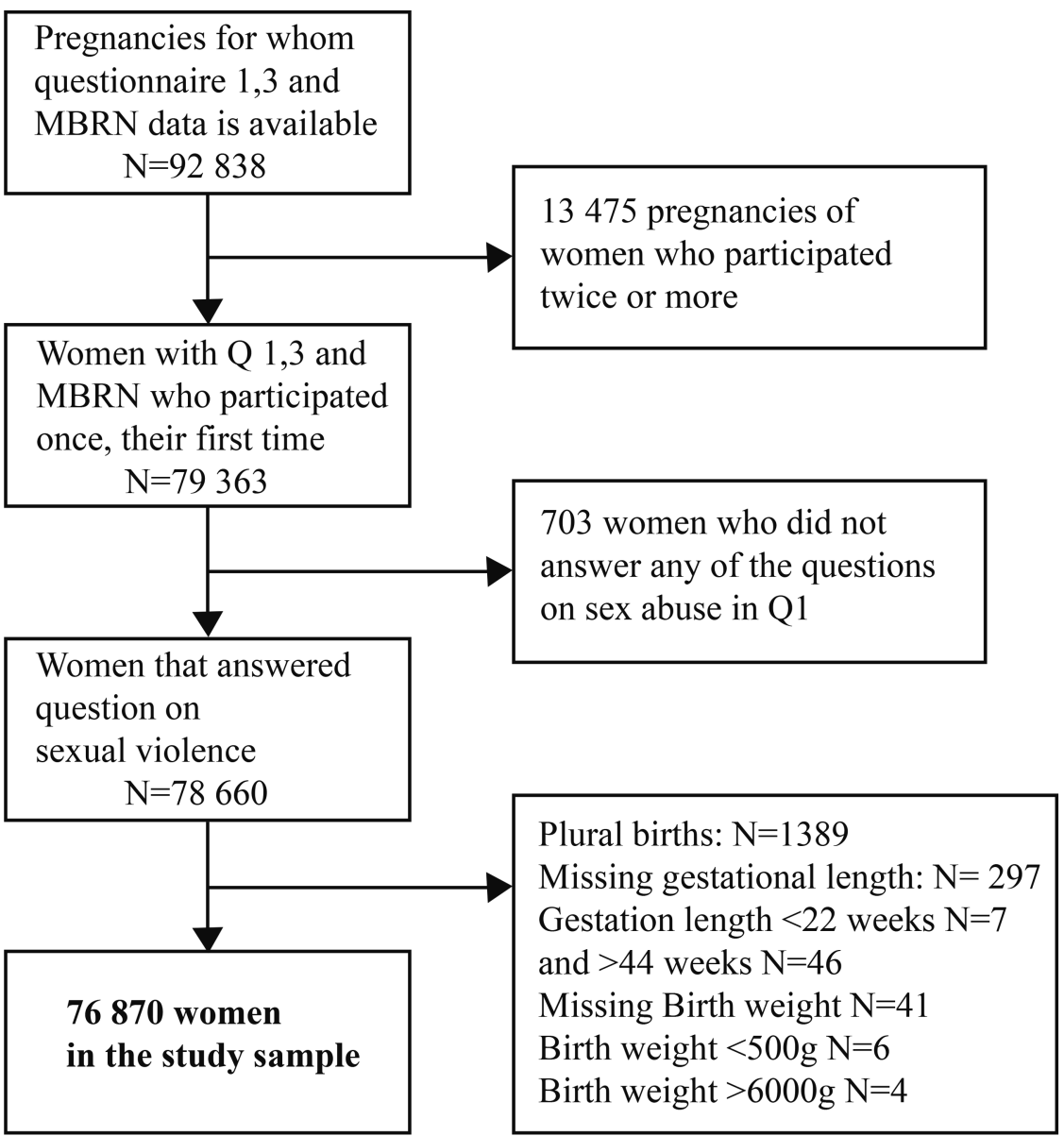

confounding factors and were adjusted for. All adjusting variables were taken from the MoBa. In Q1, age was categorised into five groups: younger than 20 years, 2024 years, 25-29 years, 30-34 years or 35 years and older. As a proxy for socioeconomic status, we used the woman's education in years (categorised into 4 groups): primary (<12 years), secondary (12 years), higher education $\leq 4$ years (13-16 years) and higher education $>4$ years $(\geq 17$ years). Parity was dichotomised into nulliparous and multiparous women. Smoking was categorised as no smoking or smoking, which included daily and occasional smoking. BMI was grouped into four categories: $<20,20-24.9,25.0-29.9$ or $\geq 30.0 \mathrm{~kg} / \mathrm{m}^{2}$. We also adjusted for mental distress because it is considered to be associated with the exposure as well as the outcome. ${ }^{4} 5$ Mental distress was measured using five items from the Hopkins symptoms checklist (SCL-5) with a cut-off at $\geq 2.0$ points, as suggested by Strand et $a l^{26}$ and obtained from Q3.

Owing to the co-occurrence of different violence types, ${ }^{7}$ we examined the effect of physical and emotional abuse as a child or as an adult in the multivariable statistical models. Information on adult physical violence was taken from Q1 and consisted of a positive answer to whether women as adults had experienced being slapped, hit, kicked or otherwise physically abused.
Child physical violence was taken from Q3 and consisted of a positive answer to the question "Have you experienced physical violence before the age of 18?" Emotional abuse as a child $(<18)$ or as an adult $(\geq 18)$ consisted of a positive answer to either, "Someone has over a long period of time systematically tried to subdue, degrade or humiliate you" or "Someone has threatened to hurt you or someone close to you", or both.

Previous PTB and inadequate antenatal care are considered to be associated with the exposure and the outcomes. $^{255}$ As a previous PTB may be a result of sexual violence prior to the related pregnancy, we did not control for a previous PTB. In Norway, the majority of women attend antenatal care, a free and well-integrated part of the public health system; therefore, we did not control for antenatal care. Ethnicity was not considered a relevant covariate in our study because the majority of the MoBa participants are ethnic Norwegian.

\section{Statistical analysis}

Characteristics were presented as percentages within the entire sample and the different outcomes. Linear regression was performed to assess differences in birth weight and gestational age for children born to women with and without a history of mild, moderate and severe sexual violence. The association between sexual violence 
and PTB, LBW and SGA was estimated with crude and AORs using logistic regression analysis. Sexual violence was analysed as a categorical variable: $1=$ mild sexual violence, $2=$ moderate sexual violence and $3=$ severe sexual violence with no sexual violence as the reference group. All analyses were adjusted for maternal age, parity, education, smoking, BMI and mental distress in the first step. Birth weight was additionally adjusted for gestational age. We further adjusted for other types of violence in the second step. We initially tested the correlation between other types of violence and sexual violence because of co-occurrence, and all Pearson's correlation coefficients were below the generally accepted cut-off of $<0.4$ for use as a covariate in the regression analyses. ${ }^{27}$ Post protocol, we stratified the sample into spontaneous start of birth and provider-initiated start of birth (induced start of birth or elective caesarean section) for gestational age because a provider-initiated start could influence the time point of birth. Information on how the birth started was taken from MBRN. We additionally performed a sensitivity analysis in which we examined the association between sexual violence and SGA and LBW among women who had a spontaneous birth at term ( $\geq 37$ weeks) because we wanted to examine the effect of violence in a group of women who were considered to be low risk according to gestational age and start of birth. When we examined the timing of the sexual violence, we compared women who were exposed to recent sexual violence (within the last 12 months) and those exposed to previous sexual violence to non-abused women. We also examined the timing among women reporting recent and previous severe sexual violence (rape) for all outcomes. The prevalence of missing data was generally low with $2.5 \%$ for BMI, $3.7 \%$ for education and $0.7 \%$ for smoking during pregnancy. Owing to this, no imputing methods for missing data were used, ${ }^{28}$ except for the missing data for the SCL-5 $(3.2 \%)$, which were replaced by the series mean. The results of the logistic regression analyses remained approximately the same when performed with the complete exclusion of missing data compared with using the imputed missing data for SCL-5.

The comparison group for all analyses was women not reporting any sexual violence. All analyses were performed with the statistical package SPSS for WINDOWS (SPSS Inc, Chicago, Illinois, USA) V.18. p values $<0.05$ were considered statistically significant.

\section{RESULTS}

The mean gestational age at birth in the total sample was 279.6 days (SD 11.9 days), and the mean birth weight was $3592.7 \mathrm{~g}$ (SD $547.1 \mathrm{~g}$ ). Table 1 displays the characteristics in the total sample and by the different outcomes.

The prevalence of adverse neonatal outcomes was generally highest in the youngest $(<20$ years $)$ and the oldest age groups ( $\geq 35$ years) among smokers and women with primary school education. A BMI $\geq 30$ was associated with PTB and LBW and BMI $<20$ with SGA. Women who reported mental distress also reported more PTB, LBW and SGA.

Among the 76870 women enrolled, 9263 (12.1\%) reported a history of mild sexual violence, 2102 (2.8\%) moderate and $2746(3.5 \%)$ severe. Women with a history of sexual violence were significantly younger and were more likely to have had primary school education. Additionally, these women more frequently reported smoking, a BMI $\geq 30$ and mental distress. These women more often experienced other types of violence as children and also as adults (data not provided in tables).

A lower gestational age at birth was observed for newborns from women who reported moderate and severe sexual violence of approximately 2 days when birth was provider-initiated (table 2 ).

Among women with a spontaneous start of birth, the gestational age was approximately one half of a day shorter when women reported severe sexual violence. These findings were significant in an adjusted analysis. A crude analysis showed that women who reported a history of severe violence delivered on average $38.3 \mathrm{~g}$ lighter children, a difference that disappeared when controlling for gestational age, mother's age, parity, education, smoking, BMI and mental distress. There were no differences regarding birth weight between women with a history of mild or moderate sexual violence compared with non-abused women.

Results from the logistic regression analysis are presented in table 3 .

Women who reported severe sexual violence had higher odds of PTB, LBW and SGA in a crude analysis, an association that was attenuated and no longer significant when adjusted for maternal age, parity, education, smoking, BMI and mental distress. Other types of violence, as a child and as an adult, had small attenuating effects on the ORs and were not included in the final models.

The sensitivity analysis, in which we examined the association between a history of sexual violence and SGA and LBW in a subsample of women who had a spontaneous term birth, showed the same pattern as in the total sample reported in table 3. Women who reported severe sexual violence had higher odds of LBW and SGA in a crude analysis but not in the adjusted analysis (data not provided in tables).

A crude analysis was used to examine if the timing of the violence was associated with adverse outcome. Women who reported recent sexual violence had a higher risk for LBW (OR 1.60 95\% CI 1.04 to 2.17) compared with non-abused women. The association was no longer significant in the adjusted analysis. In our study, $684(0.9 \%)$ women reported recent sexual violence (mild, moderate and severe) and 13487 (17.5\%) previous sexual violence (see online supplementary table S2). 
Table 1 Background characteristics in the total sample and by PTB: gestational age <week 37, LBW: weight $<2500 \mathrm{~g}$ and SGA weight below the 10th percentile by gestational age at birth in the Mother and Child Cohort

\begin{tabular}{|c|c|c|c|c|}
\hline & $\begin{array}{l}\text { Total } \\
\mathrm{N}=76870 \\
\%\end{array}$ & $\begin{array}{l}\text { PTB } \\
\mathrm{N}=3620 \\
\%\end{array}$ & $\begin{array}{l}\text { LBW } \\
\mathrm{N}=\mathbf{2 1 0 7} \\
\%\end{array}$ & $\begin{array}{l}\text { SGA } \\
\mathrm{N}=6257 \\
\% \\
\end{array}$ \\
\hline \multicolumn{5}{|l|}{ Age } \\
\hline$<20$ & 1.5 & 2.2 & 2.6 & 1.9 \\
\hline $20-24$ & 12.2 & 12.7 & 13.8 & 13.2 \\
\hline $25-29$ & 36.2 & 34.6 & 34.8 & 36.4 \\
\hline $30-34$ & 35.7 & 33.7 & 33.2 & 34.2 \\
\hline$\geq 35$ & 14.4 & 16.7 & 15.6 & 14.3 \\
\hline \multicolumn{5}{|l|}{ Education } \\
\hline Primary & 2.4 & 3.1 & 3.9 & 2.7 \\
\hline Secondary & 34.8 & 38.5 & 38.8 & 35.0 \\
\hline Higher $\leq 4$ years & 37.8 & 35.6 & 37.3 & 36.1 \\
\hline Higher $>4$ years & 21.3 & 19.2 & 20.5 & 22.2 \\
\hline Missing & 3.7 & 3.6 & 3.7 & 3.9 \\
\hline \multicolumn{5}{|l|}{ Parity } \\
\hline Nulliparous & 54.9 & 61.7 & 68.2 & 70.7 \\
\hline Multiparous & 45.1 & 38.3 & 31.8 & 29.3 \\
\hline \multicolumn{5}{|l|}{ Smoking } \\
\hline No & 90.9 & 89.3 & 85.8 & 85.6 \\
\hline Yes & 8.5 & 10.1 & 13.6 & 13.6 \\
\hline Missing & 0.7 & 0.6 & 0.6 & 0.7 \\
\hline \multicolumn{5}{|c|}{ Prepregnancy body mass index } \\
\hline$<20$ & 12.4 & 12.8 & 15.6 & 19.1 \\
\hline $20-24.9$ & 54.9 & 49.9 & 50.8 & 55.6 \\
\hline 25-29.9 & 21.0 & 22.0 & 19.0 & 15.2 \\
\hline$\geq 30$ & 9.2 & 12.6 & 11.8 & 7.6 \\
\hline Missing & 2.5 & 2.7 & 2.9 & 2.4 \\
\hline \multicolumn{5}{|l|}{ Mental distress } \\
\hline No & 93.3 & 92.3 & 91.3 & 92.3 \\
\hline Yes & 6.8 & 7.7 & 8.7 & 7.7 \\
\hline \multicolumn{5}{|c|}{ Adult physical violence } \\
\hline No & 85.5 & 83.9 & 83.6 & 84.7 \\
\hline Yes & 14.5 & 16.1 & 16.4 & 15.3 \\
\hline \multicolumn{5}{|c|}{ Child physical violence } \\
\hline No & 94.5 & 94.4 & 94.1 & 94.3 \\
\hline Yes & 5.5 & 5.6 & 5.9 & 5.5 \\
\hline \multicolumn{5}{|c|}{ Adult emotional abuse } \\
\hline No & 83.6 & 82.1 & 81.3 & 82.5 \\
\hline Yes & 16.4 & 17.9 & 18.7 & 17.5 \\
\hline \multicolumn{5}{|c|}{ Child emotional abuse } \\
\hline No & 86.2 & 85.1 & 84.7 & 85.5 \\
\hline Yes & 13.8 & 14.9 & 15.3 & 14.5 \\
\hline
\end{tabular}

There was no association between recent severe sexual violence (rape) and adverse neonatal outcome (see online supplementary Table S3). There were $66(0.1 \%)$ women who reported recent rape in this study.

\section{DISCUSSION}

Main outcome

We found that moderate and severe sexual violence were associated with a reduction in gestational age at birth. The largest effect was observed when birth was providerinitiated among women exposed to moderate or severe violence. These women had an approximately two-day reduction in gestational age. There was no significant association between sexual violence and PTB, LBW or SGA in the adjusted analysis.

\section{Strength}

This study, based on information from a large population-based study, the MoBa, which is linked to the MBRN, gave a unique opportunity to assess the association between sexual violence and outcome for newborns. The validity of the data in MoBa has in earlier research been described as sufficient for large-scale 
Table 2 Differences in gestational age for spontaneous and provider-initiated start of birth and birth weight for non-exposed women and women exposed to mild, moderate or severe sexual violence

\begin{tabular}{|c|c|c|c|c|}
\hline & $\begin{array}{l}N=76870 \\
(\%)\end{array}$ & Mean & $\begin{array}{l}\text { Crude estimate } \\
\beta(95 \% \mathrm{CI})\end{array}$ & $\begin{array}{l}\text { Adjusted estimate } \\
\beta(95 \% \mathrm{Cl})^{\star}\end{array}$ \\
\hline \multicolumn{5}{|l|}{ Gestational age } \\
\hline No sexual violence & 62699 (81.6) & 279.7 days & 1 & 1 \\
\hline Mild sexual violence & $9263(12.1)$ & & & \\
\hline Spontaneous start & $7323(11.5)$ & 279.9 days & $0.09(-0.16$ to 0.33$)$ & $0.22(-0.04$ to -0.48$)$ \\
\hline Provider-initiated start & $1940(12.5)$ & 280.3 days & $0.36(-0.37$ to 1.08$)$ & $0.64(-0.11$ to 1.39$)$ \\
\hline Moderate sexual violence & $2162(2.8)$ & & & \\
\hline Spontaneous start & $1670(2.7)$ & 279.3 days & $-0.40(-0.87$ to 0.06$)$ & $-0.28(-0.78$ to 0.21$)$ \\
\hline Provider-initiated start & 492 (3.2) & 277.6 days & $-2.13(-3.41$ to -0.84$)$ & $-2.02(-3.39$ to -0.67$)$ \\
\hline Severe sexual violence & $2746(3.6)$ & & & \\
\hline Spontaneous start & 2048 (3.3) & 278.7 days & $-0.91(-1.37$ to -0.44$)$ & $-0.65(-1.15$ to -0.16$)$ \\
\hline Provider-initiated start & $698(4.5)$ & 277.5 days & $-2.24(-3.47$ to -1.01$)$ & $-1.92(-3.22$ to -0.62$)$ \\
\hline \multicolumn{5}{|l|}{ Birth weight } \\
\hline No sexual violence & 62699 (81.6) & $3594 \mathrm{~g}$ & 1 & 1 \\
\hline Mild sexual violence & $9263(12.1)$ & $3597 \mathrm{~g}$ & $2.03(-9.26$ to 13.32$)$ & $0.04(-9.16$ to 9.23$) \dagger$ \\
\hline Moderate sexual violence & $2162(2.8)$ & $3582 \mathrm{~g}$ & $-13.61(-34.74$ to 7.51$)$ & $6.11(-11.30$ to 23.52$) \dagger$ \\
\hline Severe sexual violence & $2746(3.6)$ & $3556 \mathrm{~g}$ & $-38.33(-59.17$ to -17.49$)$ & $-0.76(-18.05$ to 16.53$) \dagger$ \\
\hline
\end{tabular}

epidemiological studies. ${ }^{29}{ }^{30}$ Our study was strengthened by the fact that the information on the different outcome variables was collected prospectively from the quality-assessed MBRN. ${ }^{31}$ The outcomes in this study are part of a complex phenomenon that has several different risk factors. ${ }^{2}$ The setting in this study, with small social and health inequalities, may therefore be suitable to isolate the effect of sexual violence on adverse neonatal outcomes.

\section{Limitations}

There are also limitations to our study. The participation rate of $40.6 \%$ in MoBa is low, and MoBa suffers to some extent from selection bias. The women included in the study are older, have more education, smoke less and are less likely to be of a non-Norwegian origin than the Norwegian population. Although it is likely that there is a socioeconomic gradient that influences prevalence estimates, a recent study by Nilsen et $a \rho^{2}$ found no evidence that the exposure-outcome associations in the MoBa study were affected by selection bias. This socioeconomic gradient may also limit the generalisability of our findings. The lack of a validated instrument for measuring the exposure is a limitation to this study, and violence measured in modules as part of a larger questionnaire, as that in MoBa, may achieve a lower

Table 3 Odds of PTB, LBW and SGA with 95\% Cls according to the different levels of sexual violence

\begin{tabular}{|c|c|c|c|c|}
\hline & $\mathbf{N}(\%)$ & Prevalence (\%) & $\begin{array}{l}\text { Crude OR } \\
(95 \% \mathrm{Cl})\end{array}$ & $\begin{array}{l}\text { Adjusted OR } \\
(95 \% \mathrm{Cl})^{\star}\end{array}$ \\
\hline PTB & & $3620(4.7)$ & & \\
\hline No sexual violence & $62699(81.6)$ & $2931(4.7)$ & 1 & 1 \\
\hline Mild sexual violence & $9263(12.1)$ & $412(4.4)$ & $0.95(0.85$ to 1.06$)$ & $0.93(0.83$ to 1.03$)$ \\
\hline Moderate sexual violence & $2162(2.8)$ & $115(5.3)$ & 1.15 (0.95 to 1.39$)$ & $1.14(0.93$ to 1.39$)$ \\
\hline Severe sexual violence & $2746(3.6)$ & $162(5.9)$ & 1.28 (1.08 to 1.51$)$ & $1.15(0.97$ to 1.37$)$ \\
\hline LBW & & $2107(2.7)$ & & \\
\hline No sexual violence & 62699 (81.6) & $1681(2.7)$ & 1 & 1 \\
\hline Mild sexual violence & $9263(12.1)$ & $257(2.8)$ & $1.04(0.91$ to 1.18$)$ & $0.98(0.85$ to 1.12$)$ \\
\hline Moderate sexual violence & $2162(2.8)$ & 75 (3.5) & 1.30 (1.03 to 1.65$)$ & $1.19(0.93$ to 1.53$)$ \\
\hline Severe sexual violence & $2746(3.6)$ & $94(3.4)$ & 1.29 (1.04 to 1.59$)$ & $1.07(0.85$ to 1.34$)$ \\
\hline SGA & & $6257(8.1)$ & & \\
\hline No sexual violence & 62699 (81.6) & $5061(8.1)$ & 1 & 1 \\
\hline Mild sexual violence & $9263(12.1)$ & 768 (8.3) & 1.03 (0.95 to 1.12$)$ & $1.00(0.91$ to 1.08$)$ \\
\hline Moderate sexual violence & $2162(2.8)$ & $178(8.3)$ & $1.02(0.87$ to 1.19$)$ & 0.95 (0.80 to 1.12$)$ \\
\hline Severe sexual violence & $2746(3.6)$ & $250(9.1)$ & $1.14(1.00$ to 1.30$)$ & $1.05(0.91$ to 1.21$)$ \\
\hline
\end{tabular}

${ }^{*}$ Adjusted for maternal age, parity, education, smoking, body mass index and mental distress.

LBW, low birth weight; PTB, preterm birth; SGA, small for gestational age. 
disclosure rate. ${ }^{5}$ However, a similar prevalence to that found in our study was reported in a Nordic study examining sexual violence and health. ${ }^{33}$ The exposure was measured in gestational week 17 , and sexual violence during pregnancy after this is therefore not included. In addition, we have no information on the context and frequency of the violence or information regarding the perpetrator.

To our knowledge, no studies have examined the influence of lifetime sexual violence reported during pregnancy on the gestational age at birth for newborns. There were minor differences in the gestational age between abused and non-abused women in this study, and the clinical importance of our findings for the health of the newborn is most likely limited. However, the difference between the provider-initiated and spontaneous initiation of birth may be of interest. Shorter provider-initiated pregnancies may suggest an increase in elective inductions and elective caesarean sections for those exposed to violence. This is supported by others $^{34} 35$ and in our previous study on sexual violence and maternal outcome. ${ }^{36}$ Studies have emphasised the meaning of control for abused women when giving birth, ${ }^{37}$ and choosing a planned start of birth may help the abused women remain in control.

Unlike the current meta-analysis (not yet published) mentioned in a WHO report, ${ }^{5}$ we did not find sexual violence to be associated with PTB and LBW in adjusted analysis. To our knowledge, no study has found an association between violence and SGA. The studies included in the meta-analysis were limited to sexual and/or physical intimate partner violence. However, our findings are supported by a Canadian population-based study with a sample of 6421 pregnant women ${ }^{17}$ and a prospective cohort study including 1555 women from the US. ${ }^{15}$ The exposure in these studies was physical and sexual violence prior to pregnancy and in pregnancy without being limited to an intimate partner. ${ }^{15}{ }^{17}$ These studies showed no association between violence and PTB or LBW.

The nature of the exposure measured in the MoBa study makes it difficult to directly compare our findings to others, mainly because we examined lifetime sexual violence by any perpetrator, not limited to intimate partner. Sexual violence is considered to be traumatic for the victim regardless of whether the perpetrator is a partner or not. ${ }^{38}$ When an intimate partner is the perpetrator, sexual violence may in addition be accompanied by controlling behaviour and include physical and emotional abuse. ${ }^{38}$ Rape by strangers is usually a single violent event with a higher risk of physical injury. Both forms of violence are associated with adverse health effects, ${ }^{5}{ }^{38}$ but the effect may differ. Unfortunately, we were not able to examine the effect of the perpetrator in this study because the MoBa study does not provide this information. However, research suggests that a substantial proportion of sexual violence occurs within an intimate relationship. ${ }^{38}$ It is not unlikely that the question about severe sexual violence (rape) primarily reflects non-partner sexual abuse and that mild sexual violence (pressured to sexual acts) may be a more psychological exposure. Our crude analyses showed different results, with a significantly higher OR for adverse neonatal outcome among women who reported severe sexual violence, thus supporting the idea that the different levels of violence are different exposures. The use of a more comprehensive instrument when measuring the exposure, with multiple response options regarding context, frequency and perpetrator would have clarified this further and provided more comprehensive knowledge about the nature of the violence. Nevertheless, we had the opportunity to control for emotional and physical abuse in preliminary analysis and this did not change the ORs.

The prevalence of abuse during pregnancy is small in our study and may have decreased the power to detect an association between violence during pregnancy and adverse neonatal outcomes, an association that is supported by other studies. ${ }^{10} 143940$ Living in an abusive relationship may have stopped women from disclosing the violence. In our study, sexual violence was assessed approximately in gestational week 17 , and events of violence after that have been missed. Some studies suggest that the risk of sexual violence may increase with the length of the pregnancy for women who are exposed. ${ }^{41}$ The studies that report the highest prevalence of violence have measured this several times during pregnancy. ${ }^{6}$ Studies have reported a violence prevalence during pregnancy of between $3 \%$ and $19 \%,{ }^{6}{ }^{42}$ including physical and sexual violence. Under-reporting among the non-exposed may have caused a misclassification that has diminished the associations between sexual violence and neonatal outcomes in our study. Since the exposure was collected before the outcome, it is unlikely that misclassification was related to the outcome, thus resulting in a non-differential misclassification that has biased the result towards the null. However, our prevalence of recent sexual $(0.9 \%)$ violence is similar to the prevalence of $1 \%$ reported in a survey that assessed intimate partner violence among a representative sample of Norwegian women. ${ }^{43}$ This number reflects the prevalence of sexual violence reported during the last year.

Several pathways between sexual violence and adverse neonatal outcomes are suggested, direct as well as indirect. ${ }^{5}$ The direct pathway of violence during pregnancy can cause immediate complications such as bleeding, rupture of membranes and $\mathrm{PTB}$, and examples of indirect pathways include more health-risk behaviours, depression and stress/anxiety. ${ }^{5}{ }^{44}$ Experienced violence and living in an abusive environment can both cause increased stress levels, which could be on the pathway between abuse and adverse neonatal outcome. Maternal exposure to stress can influence the hypothalamic pituitary adrenal axis hormones, and it is suggested that changes in these hormones may cause negative outcomes, such as a reduction in gestational age and fetal 
growth restriction. ${ }^{45}$ It has been proposed that mental distress and symptoms of depression are on the causal pathway between violence and adverse health outcome, yet it has also been suggested that women with mental health difficulties are more likely to be victims of violence. ${ }^{46}$ As the relationship may be bidirectional, we chose to control for mental distress in our study. Similarly, the health-risk behaviours, smoking and BMI may be on the pathway between sexual violence and neonatal outcome. Nevertheless, we kept these covariates in the regression analysis because they are especially related to birth weight and PTB. ${ }^{3} 47$

\section{CONCLUSION}

Overall, our findings provide no evidence for an association between lifetime sexual violence and adverse neonatal outcomes. A small significant effect on the gestational age at birth was detected, but the clinical importance of this is most likely limited for the health of the newborn. PTB, LBW and SGA all have complex origins with multiple possible pathways. ${ }^{1}{ }^{2}$ Although we did not find an association between sexual violence and PTB, LBW or SGA in adjusted analyses, crude analyses in our study suggested that sexual violence may be a risk factor for adverse neonatal outcomes for some women; however, for the majority of women, the relationship was confounded by other risk factors. It is possible that these factors were the result of prior exposure to violence, but this could not be assessed in this study. Antenatal care is one of the most important entry points in which women seek healthcare without necessarily disclosing ongoing exposure to violence or a history of sexual violence. It is recommended that caregivers and clinicians ask women about exposure to violence when assessing conditions that may be complicated by violence. ${ }^{48}$ More knowledge about this condition is needed. Additionally, antenatal care may offer opportunities for women to receive help if they are exposed to violence and also in providing assistance to change behavioural factors contributing to adverse outcomes.

\footnotetext{
Author affiliations

${ }^{1}$ Section of Obstetrics, Department for Women's and Children's Health, Oslo University Hospital, Oslo, Norway

${ }^{2}$ Department of Public Health and General Practice, Faculty of Medicine, The Norwegian University of Science and Technology (NTNU), Trondheim, Norway ${ }^{3}$ Department of Obstetrics and Gynecology, St. Olavs Hospital, Trondheim University Hospital, Trondheim, Norway

${ }^{4}$ Department for Women's and Children's Health, National Resource Centre for Women's Health, Oslo University Hospital, Oslo, Norway

${ }^{5}$ Department of Health, Nutrition and Management, Faculty of Health Sciences, Oslo and Akershus University College of Applied Sciences, Oslo, Norway
}

Acknowledgements The authors are grateful to all the participating families in Norway who took part in this on-going cohort study.

Contributors LH contributed in the conception and design of the study, performed the analysis and drafted the manuscript. BS contributed in the conception of the study, advised on the statistical analyses and drafting of the manuscript. SV advised on the statistical analyses and the drafting of the manuscript. ML contributed in the conception and design of the study, advised on the statistical analyses and participated in drafting the manuscript. All authors read and approved the final version.

Funding The Norwegian Mother and Child Cohort Study is supported by the Norwegian Ministry of Health and the Ministry of Education and Research, NIH/NIEHS (contract no. N01-ES-75558), NIH/NINDS (grant no.1 U01 NS 047537-01 and grant no.2 U01 NS 047537-06A1) and the Norwegian Research Council/FUGE (grant no. 151918/S10). LH is supported by SouthEastern Norway Regional Health Authority (grant no. 2012010) and ML is supported by the Research Council of Norway (grant no. 204292/H10).

\section{Competing interests None.}

Patient consent Obtained.

Ethics approval The Regional Committee for Medical Research Ethics (Ref. SAFH 95/313 RTL) and the Norwegian Data Inspectorate approved the study.

Provenance and peer review Not commissioned; externally peer reviewed.

Data sharing statement No additional data are available.

Open Access This is an Open Access article distributed in accordance with the Creative Commons Attribution Non Commercial (CC BY-NC 4.0) license, which permits others to distribute, remix, adapt, build upon this work noncommercially, and license their derivative works on different terms, provided the original work is properly cited and the use is non-commercial. See: http:// creativecommons.org/licenses/by-nc/4.0/

\section{REFERENCES}

1. Green NS, Damus K, Simpson JL, et al. Research agenda for preterm birth: recommendations from the March of Dimes. Am J Obstet Gynecol 2005;193:626-35.

2. March of Dimes, PMNCH, Save The Children, WHO. Born too soon: the global action report on preterm birth. Geneva: World Health Organization, 2012.

3. Wilcox AJ. On the importance-and the unimportance-of birth weight. Int J Epidemiol 2001;30:1233-41.

4. Lazinski MJ, Shea AK, Steiner M. Effects of maternal prenatal stress on offspring development: a commentary. Arch Womens Ment Health 2008;11:363-75.

5. Garcia-Moreno C, Pallitto C, Devries K, et al. Global and regional estimates of violence against women: prevalence and health effects of intimate partner violence and non-partner sexual violence. Geneva: World Health Organization; 2013.

6. Campbell J, Garcia-Moreno C, Sharps P. Abuse during pregnancy in industrialized and developing countries. Violence Against Women 2004;10:770-89.

7. Garcia-Moreno C, Jansen HA, Ellsberg M, et al. Prevalence of intimate partner violence: findings from the WHO multi-country study on women's health and domestic violence. Lancet 2006;368:1260-9.

8. Sanchez SE, Alva AV, Diez CG, et al. Risk of spontaneous preterm birth in relation to maternal exposure to intimate partner violence during pregnancy in Peru. Matern Child Health J 2013;17:485-92.

9. Leeners B, Stiller R, Block E, et al. Pregnancy complications in women with childhood sexual abuse experiences. J Psychosom Res 2010;69:503-10.

10. Nunes MA, Camey S, Ferri CP, et al. Violence during pregnancy and newborn outcomes: a cohort study in a disadvantaged population in Brazil. Eur J Public Health 2011;21:92-7.

11. Rodrigues $T$, Rocha $L$, Barros $H$. Physical abuse during pregnancy and preterm delivery. Am J Obstet Gynecol 2008;198:171-6.

12. Noll JG, Schulkin J, Trickett PK, et al. Differential pathways to preterm delivery for sexually abused and comparison women. $J$ Pediatr Psychol 2007;32:1238-48.

13. Silverman JG, Decker MR, Reed E, et al. Intimate partner violence victimization prior to and during pregnancy among women residing in 26 U.S. states: associations with maternal and neonatal health. Am J Obstet Gynecol 2006;195:140-8.

14. Murphy CC, Schei B, Myhr TL, et al. Abuse: a risk factor for low birth weight? A systematic review and meta-analysis. CMAJ 2001;164:1567-72.

15. Fried LE, Cabral $\mathrm{H}$, Amaro $\mathrm{H}$, et al. Lifetime and during pregnancy experience of violence and the risk of low birth weight and preterm birth. J Midwifery Womens Health 2008;53:522-8.

16. Janssen PA, Holt VL, Sugg NK, et al. Intimate partner violence and adverse pregnancy outcomes: a population-based study. $A m \mathrm{~J}$ Obstet Gynecol 2003;188:1341-7. 
17. Urquia ML, O'Campo PJ, Heaman MI, et al. Experiences of violence before and during pregnancy and adverse pregnancy outcomes: an analysis of the Canadian Maternity Experiences Survey. BMC Pregnancy Childbirth 2011;11:42.

18. Altarac M, Strobino D. Abuse during pregnancy and stress because of abuse during pregnancy and birthweight. J Am Med Womens Assoc 2002;57:208-14.

19. Cokkinides VE, Coker AL, Sanderson M, et al. Physical violence during pregnancy: maternal complications and birth outcomes. Obstet Gynecol 1999;93:661-6.

20. Grimstad H, Schei B, Backe B, et al. Physical abuse and low birthweight: a case-control study. Br J Obstet Gynaecol 1997;104:1281-7.

21. Kaye DK, Mirembe FM, Bantebya G, et al. Domestic violence during pregnancy and risk of low birthweight and maternal complications: a prospective cohort study at Mulago Hospital, Uganda. Trop Med Int Health 2006;11:1576-84.

22. Magnus $\mathrm{P}$, Irgens LM, Haug K, et al. Cohort profile: the Norwegian Mother and Child Cohort Study (MoBa). Int $J$ Epidemiol 2006;35:1146-50.

23. Lukasse M, Henriksen L, Vangen S, et al. Sexual violence and pregnancy-related physical symptoms. BMC Pregnancy Childbirth 2012;12:83.

24. Henriksen L, Vangen S, Schei B, et al. Sexual violence and antenatal hospitalization. Birth 2013;40:281-8.

25. Skjaerven R, Gjessing HK, Bakketeig LS. et al. Birthweight by gestational age in Norway. Acta Obstet Gynecol Scand 2000;79:440-9.

26. Strand $\mathrm{BH}$, Dalgard OS, Tambs K, et al. Measuring the menta health status of the Norwegian population: a comparison of the instruments SCL-25, SCL-10, SCL-5 and MHI-5 (SF-36). Nord J Psychiatry 2003;57:113-18.

27. Field A. Discovering statistics using SPSS. Los Angeles: SAGE, 2009.

28. Veierød MB, Lydersen S, Laake P, et al. Medical statistics: in clinical and epidemiological research. Oslo: Gyldendal Akademisk, 2012.

29. Kvalvik LG, Nilsen RM, Skjaerven R, et al. Self-reported smoking status and plasma cotinine concentrations among pregnant women in the Norwegian Mother and Child Cohort Study. Pediatr Res 2012;72:101-7.

30. Furu K, Karlstad O, Skurtveit S, et al. High validity of mother-reported use of antiasthmatics among children: a comparison with a populationbased prescription database. J Clin Epidemiol 2011;64:878-84.

31. Irgens LM. The Medical Birth Registry of Norway. Epidemiological research and surveillance throughout 30 years. Acta Obstet Gynecol Scand 2000;7:435-9.

32. Nilsen RM, Vollset SE, Gjessing HK, et al. Self-selection and bias in a large prospective pregnancy cohort in Norway. Paediatr Perinat Epidemiol 2009;23:597-608.
33. Hilden M, Schei B, Swahnberg K, et al. A history of sexual abuse and health: a Nordic multicentre study. BJOG 2004;111 1121-7.

34. Nerum H, Halvorsen L, Straume B, et al. Different labour outcomes in primiparous women that have been subjected to childhood sexual abuse or rape in adulthood: a case-control study in a clinical cohort. BJOG 2013;120:487-95.

35. Lukasse M, Vangen $\mathrm{S}$, Oian $\mathrm{P}$, et al. Childhood abuse and caesarean section among primiparous women in the Norwegian Mother and Child Cohort Study. BJOG 2010;117:1153-7.

36. Henriksen L, Schei B, Vangen S, et al. Sexual violence and mode of delivery: a population-based cohort study. BJOG 2014;12: 1237-44.

37. Montgomery E. Feeling safe: a metasynthesis of the maternity care needs of women who were sexually abused in childhood. Birth 2013;40:88-95.

38. Abrahams N, Devries K, Watts C, et al. Worldwide prevalence of non-partner sexual violence: a systematic review. Lancet 2014;383:1648-54

39. Faramarzi M, Esmaelzadeh S, Mosavi S. Prevalence, maternal complications and birth outcome of physical, sexual and emotional domestic violence during pregnancy. Acta Med Iran 2005;43:115-22.

40. Valladares E, Ellsberg M, Pena R, et al. Physical partner abuse during pregnancy: a risk factor for low birth weight in Nicaragua. Obstet Gynecol 2002;100:700-5.

41. Shah PS, Shah J. Maternal exposure to domestic violence and pregnancy and birth outcomes: a systematic review and metaanalyses. J Womens Health (Larchmt) 2010;19:2017-31.

42. Sharps PW, Laughon K, Giangrande SK. Intimate partner violence and the childbearing year: maternal and infant health consequences. Trauma Violence Abuse 2007;8:105-16.

43. Neroien Al, Schei B. Partner violence and health: results from the first national study on violence against women in Norway. Scand $J$ Public Health 2008;36:161-8.

44. Leeners B, Neumaier-Wagner P, Quarg AF, et al. Childhood sexual abuse (CSA) experiences: an underestimated factor in perinatal care. Acta Obstet Gynecol Scand 2006;85:971-6.

45. Valladares E, Pena R, Ellsberg M, et al. Neuroendocrine response to violence during pregnancy-impact on duration of pregnancy and fetal growth. Acta Obstet Gynecol Scand 2009;88:818-23.

46. Devries KM, Mak JY, Bacchus LJ, et al. Intimate partner violence and incident depressive symptoms and suicide attempts: a systematic review of longitudinal studies. PLoSMed 2013;10:e1001439.

47. McDonald SD, Han Z, Mulla S, et al. Overweight and obesity in mothers and risk of preterm birth and low birth weight infants: systematic review and meta-analyses. BMJ 2010;341:3428.

48. World Health Organisation. Responding to intimate partner violence and sexual violence against women: WHO clinical and policy guidelines. Geneva: WHO, 2013. 